\title{
Synthesis and characterization of submicron-sized mesoporous aluminosilicate spheres
}

\author{
GAUTAM GUNDIAH, M ESWARAMOORTHY, S NEERAJ, \\ SRINIVASAN NATARAJAN and C N R RAO* \\ Chemistry and Physics of Materials Unit and CSIR Centre of Excellence in \\ Chemistry, Jawaharlal Nehru Centre for Advanced Scientific Research, \\ Jakkur PO, Bangalore 560064, India \\ e-mail: cnrrao@jncasr.ac.in
}

MS received 27 March 2001

\begin{abstract}
Mesoporous aluminosilicate spheres of 0.3-0.4 $\mu \mathrm{m}$ diameter, with different $\mathrm{Si} / \mathrm{Al}$ ratios, have been prepared by surfactant templating. Surface area of these materials is in the $510-970 \mathrm{~m}^{2} \mathrm{~g}^{-1}$ range and pore diameter in the $15-20 \AA$ range.
\end{abstract}

Keywords. Mesoporous solids; mesoporous aluminosilicate spheres; surfacetant templating.

\section{Introduction}

The discovery of mesoporous silica marks a major event in areas related to catalysis, sorption and separation processes ${ }^{1}$. Amongst the criteria for the use of such mesoporous materials for various purposes, morphology and particle size are important ones. In this context, several workers have attempted to prepare submicron sized mesoporous silica spheres ${ }^{2,3}$. The synthetic procedure generally makes use of Stöber's reaction involving base hydrolysis and subsequent condensation of the silicon ester in an appropriate solvent ${ }^{4}$. One of the first efforts to make spherical silica is due to Unger et $a l^{5}$, who obtained non-porous silica beads with a particle size of $\sim 3 \mu \mathrm{m}$. Kaiser and Unger ${ }^{6}$, however, obtained completely porous silica spheres by a similar procedure. Büchel et $a l^{7}$ have described a novel pathway for obtaining monodisperse silica spheres composed of a non-porous solid silica core and a thin mesoporous silica shell by taking advantage of the methods described by Unger et $a l^{5}$ and Kaiser and Unger ${ }^{6}$. By employing surfactant-stabilized emulsions as in the synthesis of MCM-41, Huo et $a l^{3}$ obtained large, monodisperse mesoporous silica spheres with high surface areas. The spheres had diameters between $0 \cdot 1$ to $2 \mathrm{~mm}$ and pore diameters of 1 to $5 \mathrm{~nm}$. Mesoporous silica spheres ranging from 2 to $6 \mu \mathrm{m}$ (pore diameter $\sim 2.5 \mathrm{~nm}$ ) have been synthesized under static acidic conditions by mixed cationic-nonionic surfactant templating as well ${ }^{8}$. Spheres of ordered MCM-41 and MCM-48 have also been prepared by employing appropriate surfactants ${ }^{9,10}$. It was our interest to

*For correspondence 
prepare monodisperse aluminosilicate spheres with mesoporous properties. We have been able to prepare such spherical aluminosilicates with nominal Si/Al ratios between 14 and 40 by employing a cationic surfactant. For the purpose of comparison, we also prepared mesoporous silica spheres by the same procedure.

\section{Experimental}

\subsection{Synthesis}

We have prepared mesoporous aluminosilicate spheres by the following procedure. In a typical synthesis, $0.667 \mathrm{~g}$ N-cetyl-N,N,N-trimethylammonium bromide $(\mathrm{CTAB})$ was dissolved in a solution containing $14 \mathrm{~mL}$ deionised water $\left(\mathrm{H}_{2} \mathrm{O}\right)$ and $14 \mathrm{~mL}$ ethanol $\left(\mathrm{C}_{2} \mathrm{H}_{5} \mathrm{OH}\right)$. To the above solution, $3.5 \mathrm{~mL}$ ammonia $\left(\mathrm{NH}_{3}\right)$ solution $(25 \%)$ was added under stirring, followed by the addition of a solution of $15 \mathrm{~mL}$ of an aqueous solution containing $0.1 \mathrm{~g} \mathrm{Al}_{2}\left(\mathrm{SO}_{4}\right)_{3}$. The final composition of the mixture was $0.4 \mathrm{M} \mathrm{CTAB} / 360 \mathrm{M} \mathrm{H}_{2} \mathrm{O} / 53 \mathrm{M} \mathrm{C}_{2} \mathrm{H}_{5} \mathrm{OH} / 41.8 \mathrm{M} \quad \mathrm{NH}_{3} / 1 \mathrm{M}$ TEOS/ $0 \cdot 04 \mathrm{M} \mathrm{Al}_{2}\left(\mathrm{SO}_{4}\right)_{3}$. After $10 \mathrm{~min}, 1 \mathrm{~mL}$ of tetraethylorthosilicate (TEOS) was added dropwise over a period of $2 \mathrm{~h}$ under stirring to obtain a gel. The gel was aged at room temperature $(298 \mathrm{~K})$ for $16 \mathrm{~h}$, filtered, washed with deionised water and dried at ambient temperature. The dried product was calcined at $200^{\circ} \mathrm{C}$ for $4 \mathrm{~h}$, which resulted in sample C. By a similar procedure, we prepared two other aluminosilicate samples (A and $\mathrm{B}$ ) with different $\mathrm{Si} / \mathrm{Al}$ ratios. Si/Al ratios in the starting compositions were 14,24 and 40 respectively in samples A, B and C. Sample D corresponds to pure silica.

\subsection{Characterization}

Powder X-ray diffraction (XRD) patterns of the samples were obtained using $\mathrm{CuK} \alpha$ radiation (Rich-Siefert, $\mathrm{XRD}-3000-\mathrm{TT}$ ). Thermogravimetric analysis (TGA) was carried out (Mettler Toledo, TG-850) in flowing oxygen atmosphere $\left(50 \mathrm{~mL} \mathrm{~min}^{-1}\right)$ at a heating rate of $10 \mathrm{k} \mathrm{min}^{-1}$. Scanning electron microscopy (SEM) and energy-dispersive X-ray (EDX) analysis were carried out using a Leica scanning electron microscope fitted with EDX spectrometer and a Link ISIS detector. Surface areas were determined by the Brunauer-Emmet-Teller (BET) method on a Belsorp 28 instrument. Pore-size distribution was calculated by the Barrett-Joyner-Halenda (BJH) method ${ }^{11}$. Solid state MAS NMR measurements were performed on a Bruker DSX-300 MHz Spectrometer. Tetramethylsilane (TMS) and $\mathrm{Al}\left(\mathrm{H}_{2} \mathrm{O}\right)_{6}{ }^{3+}$ were used as external standards.

\section{Results and discussion}

Table 1 lists the compositions of the various samples prepared by us. Calcination of the spherical aluminosilicates (A-C) and silica (D) at $200^{\circ} \mathrm{C}$ for $4 \mathrm{~h}$ removed most of the surfactant template as will be demonstrated later. In figures 1 and 2, we show the SEM images of the two aluminosilicate samples (as-synthesized and calcined) with $\mathrm{Si} / \mathrm{Al}$ ratios of 14 and 40 (A and $\mathrm{C}$ respectively). The as-synthesized sample of A with a Si/Al ratio of 14 shows spherical morphology as revealed by the SEM images. There is little agglomeration of particles. The spherical 
Table 1. Properties of mesoporous aluminosilicate spheres.

\begin{tabular}{lccccc}
\hline Sample & \multicolumn{1}{c}{$\mathrm{Si}_{\mathrm{All}}{ }^{\mathrm{a}}$} & \multicolumn{1}{c}{$d_{100}{ }^{\mathrm{b}}(\AA)$} & $\begin{array}{c}\text { Particle } \\
\text { diameter }(\mu \mathrm{m})\end{array}$ & $\begin{array}{c}\text { Surface area } \\
\left(\mathrm{m}^{2} \mathrm{~g}^{-1}\right)\end{array}$ & $\begin{array}{c}\text { Pore } \\
\text { diameter }(\AA)\end{array}$ \\
\hline $\mathrm{A}$ & $14(49)$ & $35 \cdot 8(36 \cdot 2)$ & $0 \cdot 35$ & 970 & 18 \\
$\mathrm{~B}$ & $24(82)$ & $36 \cdot 8(35 \cdot 3)$ & $0 \cdot 40$ & 510 & 15 \\
$\mathrm{C}$ & $40(132)$ & $34 \cdot 8(30 \cdot 6)$ & $0 \cdot 30$ & 700 & 19 \\
$\mathrm{D}$ & Infinity & $31 \cdot 3(29 \cdot 6)$ & $0 \cdot 43$ & 1100 & 20 \\
\hline
\end{tabular}

${ }^{\mathrm{a}}$ Values in parentheses are obtained after taking into account $\mathrm{Al}$ in the framework; b d-value of the low angle reflection in the XRD pattern. Values in parentheses were obtained after calcination at $200^{\circ} \mathrm{C}$ for $4 \mathrm{~h}$. After calcination at $473 \mathrm{~K}$ for $4 \mathrm{~h}$, the percentage of template removed in the samples is $87-95 \%$
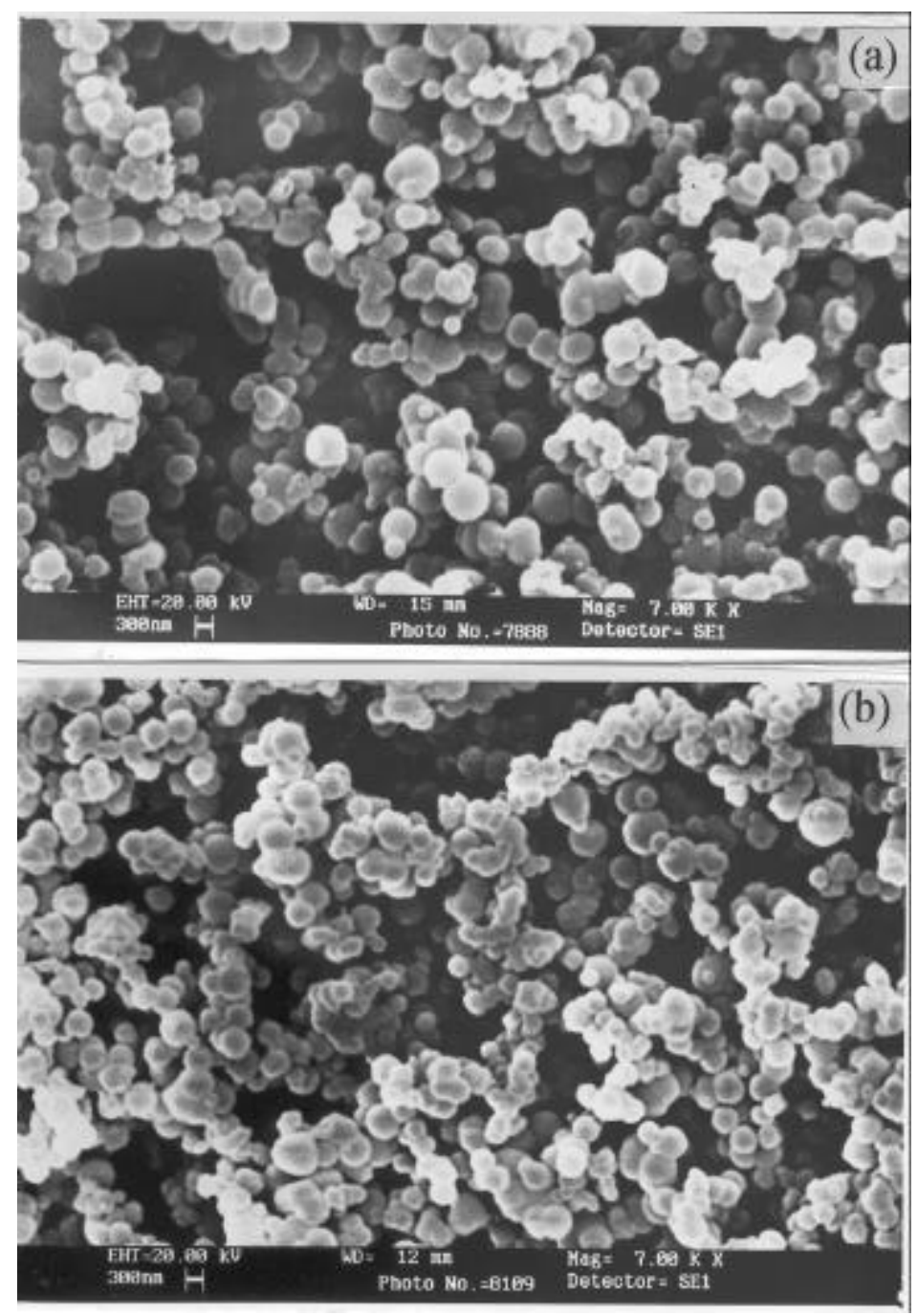

Figure 1. SEM micrographs of aluminosilicate spheres (A): (a) assynthesized and (b) after calcination at $200^{\circ} \mathrm{C}$ for $4 \mathrm{~h}$. 

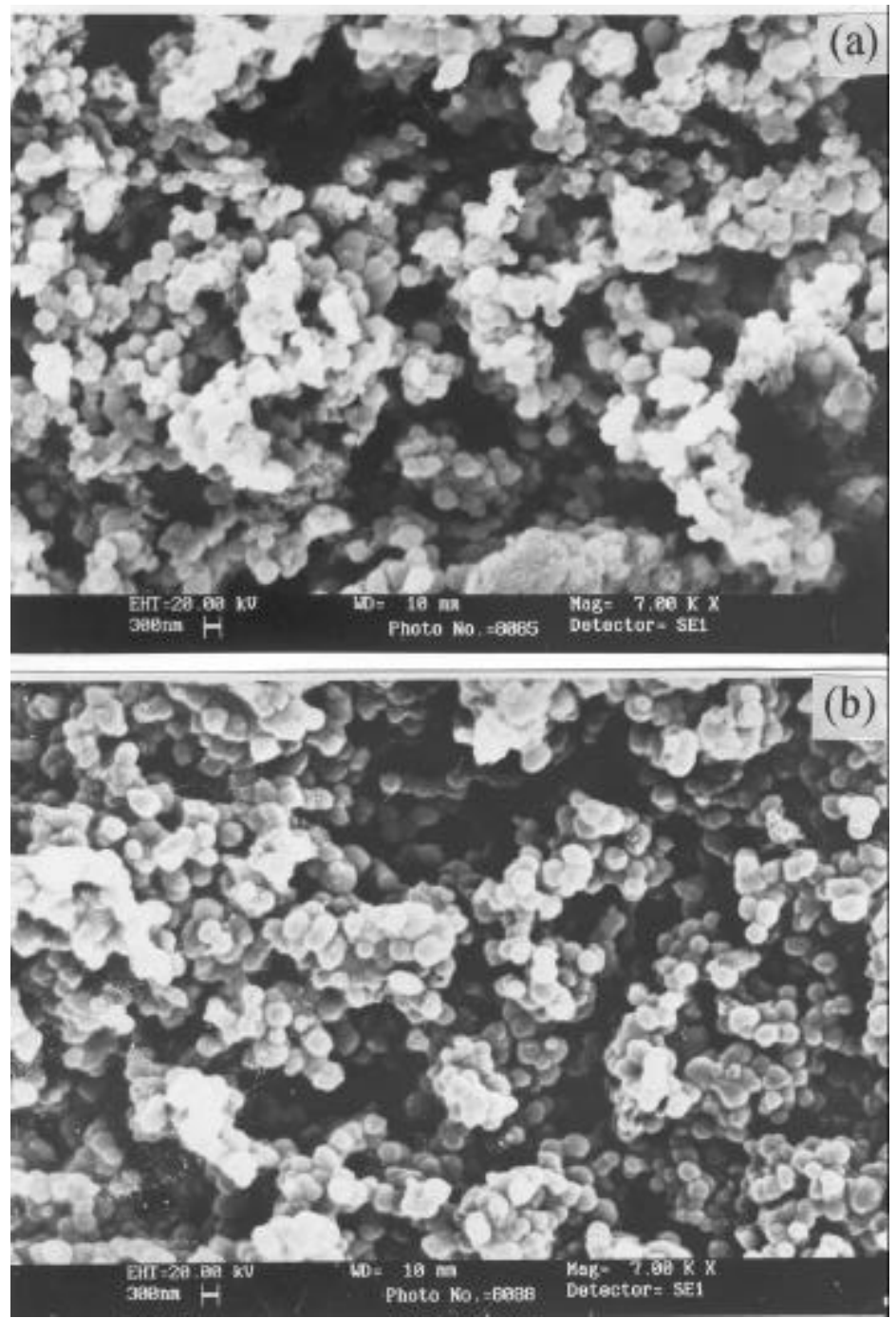

Figure 2. SEM micrographs of aluminosilicate spheres (C): (a) assynthesized and (b) after calcination at $200^{\circ} \mathrm{C}$ for $4 \mathrm{~h}$.

morphology is retained even after calcination at $200^{\circ} \mathrm{C}$, as can be seen from figure 1b. This was true of the other two aluminosilicate samples (B and C) as well, as demonstrated in figure $2 \mathrm{~b}$ in the case of sample $\mathrm{C}$. The particles show a narrow size distribution with average diameters of 0.35 and $0.30 \mu \mathrm{m}$ in the case of $\mathrm{A}$ and $\mathrm{C}$ respectively. The article sizes of all the samples are listed in table 1.

Powder XRD patterns of the as-synthesized aluminosilicate and silica spheres are presented in figure $3 \mathrm{a}$. The XRD patterns show a single peak at $2 \theta$ values of $2.46^{\circ}, 2 \cdot 38^{\circ}, 2.54^{\circ}$ and $2.81^{\circ}$ respectively for A, B, C and D. The low-angle peaks are similar to those of the hexagonal mesoporous solids. The powder XRD patterns of the samples after calcination at $200^{\circ} \mathrm{C}$ for $4 \mathrm{~h}$ exhibit single broad peaks at $2 \theta$ 

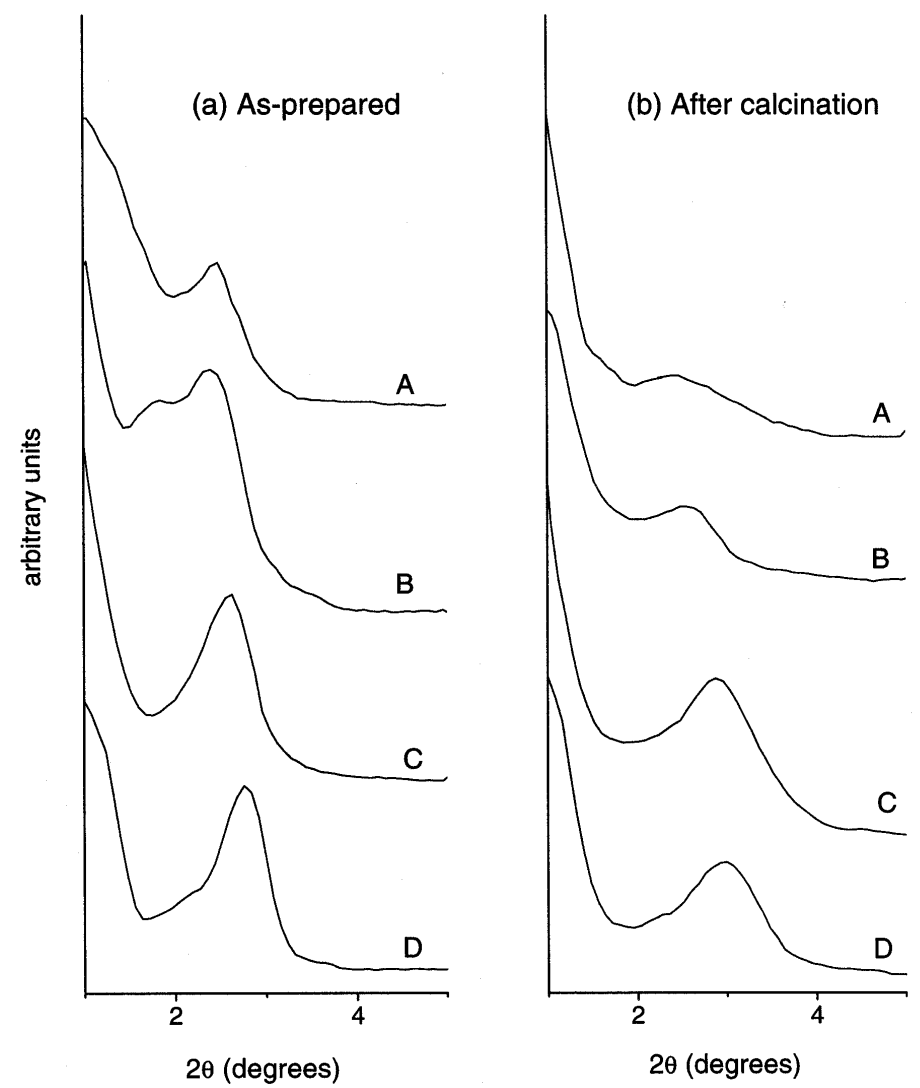

Figure 3. XRD patterns of the aluminosilicate (A, B and C) and pure silica (D) spheres: (a) as-synthesized and (b) after calcination.

values of $2.44^{\circ}, 2.5^{\circ}, 2.88^{\circ}$ and $2.98^{\circ}$ respectively for $\mathrm{A}, \mathrm{B}, \mathrm{C}$ and $\mathrm{D}$ as shown in Figure $3 \mathrm{~b}$. The shift in the peak positions after calcination is due to the removal of the template. The presence of the low-angle reflection after calcination indicates that the mesophase is reasonably intact even after the removal of the template, although the intensity is considerably diminished in the case of the samples A and B. The spherical morphology is, however, retained as mentioned earlier. It appears that Al-rich samples are more disordered.

TGA curves of the aluminosilicates $\mathrm{A}$ and $\mathrm{C}$ are shown in figure 4. The assynthesized samples show one major mass loss in the temperature range $200^{\circ}-$ $300^{\circ} \mathrm{C}$. The mass loss is around $40 \%$, where most of the template is removed. Thus, the sample calcined at $200^{\circ} \mathrm{C}$ for $4 \mathrm{~h}$, only shows a mass loss $(<20 \%)$ due to adsorbed water around $100^{\circ} \mathrm{C}$. The TGA curves confirm that most of the template is removed on calcination at $200^{\circ} \mathrm{C}$ for $4 \mathrm{~h}$. These observations are consistent with those of Tanev et $a l^{12}$, who have reported similar TGA curves for mesoporous silica before and after calcination. We did not calcine the samples at temperatures higher than $200^{\circ} \mathrm{C}$ in order to ensure that the morphology and surface area of the 

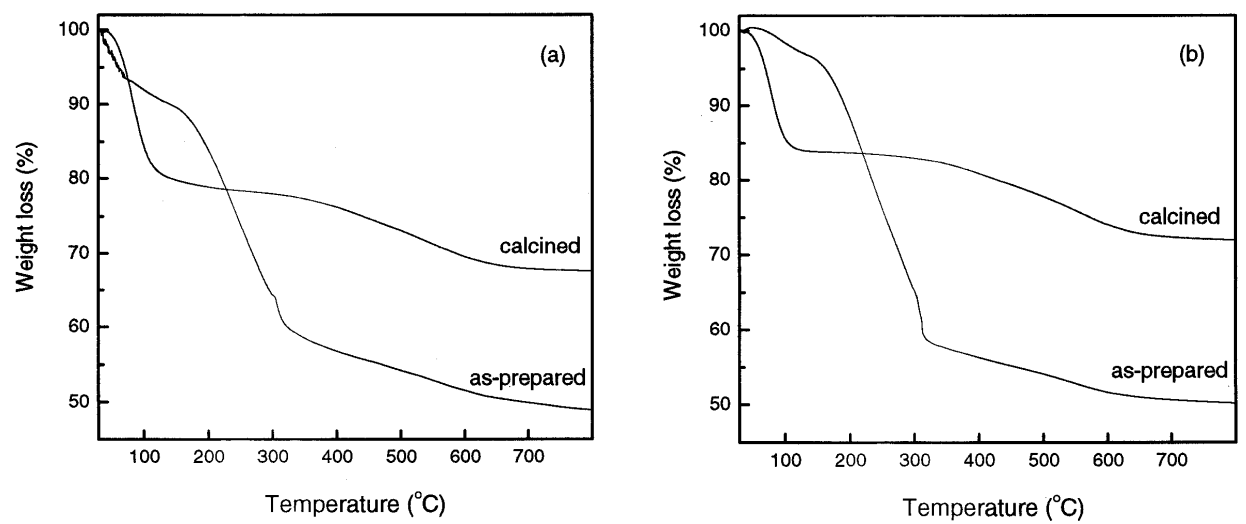

Figure 4. TGA curves of the aluminosilicate samples A (a) and C (b).
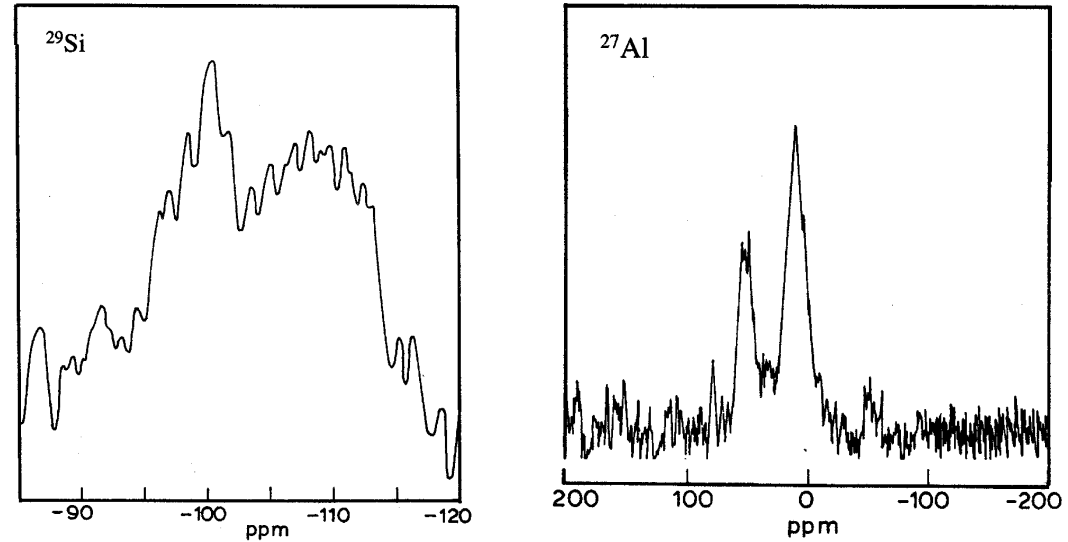

Figure 5. ${ }^{29} \mathrm{Si}$ and ${ }^{27} \mathrm{Al}$ MAS-NMR spectra of as-synthesized sample C.

samples are not badly affected. Percentage values of the template removed on calcination at $200^{\circ} \mathrm{C}$ are in the range $87-95 \%$.

${ }^{29} \mathrm{Si}$ and ${ }^{27} \mathrm{Al}$ MAS NMR measurements were carried out on the as-synthesized and calcined sample $\mathrm{C}$. In figure 5 we show the ${ }^{29} \mathrm{Si}$ and ${ }^{27} \mathrm{Al}$ MAS NMR spectra of the as-synthesized sample $\mathrm{C}$. The ${ }^{29} \mathrm{Si}$ NMR spectrum of the as-synthesized sample shows two peaks at -100 and $-108 \mathrm{ppm}$ due to the $\mathrm{Q}^{3}$ and $\mathrm{Q}^{4}$ silicate species respectively ${ }^{13}$. The intensity of the $\mathrm{Q}^{3}$ species is greater than that of the $\mathrm{Q}^{4}$ species indicating that the silanol groups have not condensed fully. On calcination, however, the relative intensity of the $\mathrm{Q}^{4}$ species increases, showing that the silanol groups condense to form the $\mathrm{Si}-\mathrm{O}-\mathrm{Si}$ species. The ${ }^{27} \mathrm{Al}$ NMR spectrum of the assynthesized samples show two peaks at 47 and $9.5 \mathrm{ppm}$. These are due to tetrahedrally and octahedrally co-ordinated species respectively ${ }^{14}$. After calcination, the relative proportion of the peaks corresponding to the tetrahedral and the octahedral species remains the same. Taking account of only the tetrahedral 

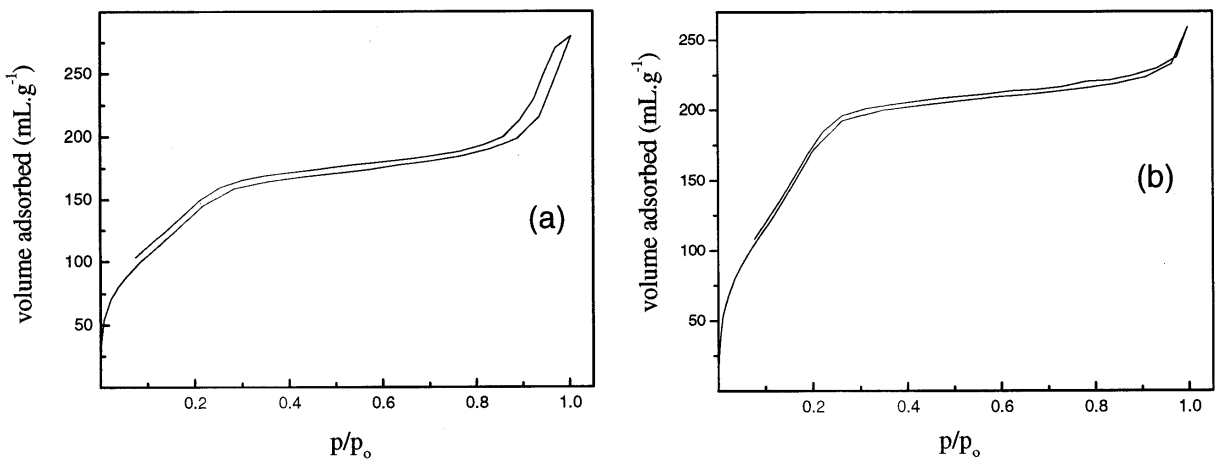

Figure 6. $\mathrm{N}_{2}$ adsorption isotherms of (a) sample A calcined at $200^{\circ} \mathrm{C}$ for $4 \mathrm{~h}$, and (b) sample $\mathrm{C}$ calcined at $200^{\circ} \mathrm{C}$ for $4 \mathrm{~h}$.
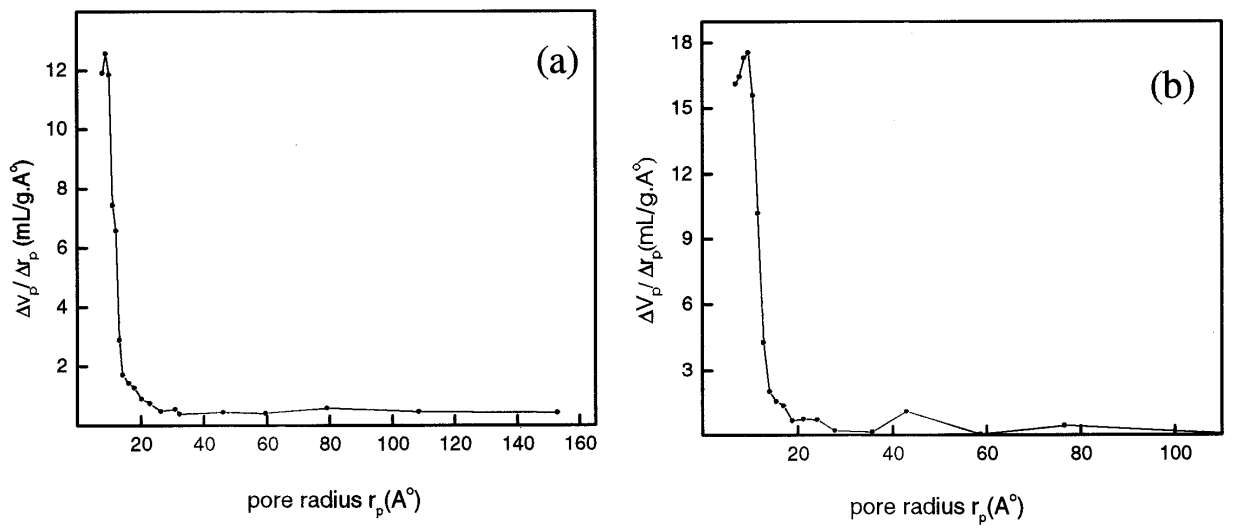

Figure 7. Pore size distribution curves of the calcined samples $\mathrm{A}(\mathbf{a})$ and $\mathrm{C}$ (b) obtained by using the BJH method.

species as a part of the framework, we estimate the percentage of aluminium in the framework to be around $30 \%$. The $\mathrm{Si} / \mathrm{Al}$ ratios calculated on this basis are listed in table 1.

Nitrogen adsorption isotherms of samples A and C are presented in figure 6. These are typical type IV adsorption isotherms. The BET surface areas of the samples calculated from $\mathrm{N}_{2}$ adsorption are in the range $500-1000 \mathrm{~m}^{2} \mathrm{~g}^{-1}$ (table 1). In general, the surface area of the aluminosilicate spheres is smaller than that of pure silica spheres. Surface area of the pure silica spheres as determined by us is $1100 \mathrm{~m}^{2} \mathrm{~g}^{-1}$, the literature ${ }^{9}$ value being $1200 \mathrm{~m}^{2} \mathrm{~g}^{-1}$. Pore size distribution was calculated using the BJH method. In figure 7, we show the plots of the pore size in case of samples $\mathrm{A}$ and $\mathrm{C}$. The particles have a narrow pore size distribution, the values of the pore diameters being in the range 15-20 A (table 1). The pore size of the aluminosilicate spheres is smaller than that of the pure silica spheres. We could estimate the diameter of the pores from the low-angle XRD peaks by making use of the relation $a_{\mathrm{o}}=\left(2 d_{100}\right) /(3)^{1 / 2}$. The values of the diameter obtained are considerably 
larger than the pore diameter from adsorption measurements, since the former includes the wall thickness. We have estimated the wall thickness from the difference in the XRD $\left(a_{0}\right)$ and adsorption pore diameters. These values are in the 7-13 A range, the thickness increasing with $\mathrm{Al}$ content.

\section{Conclusions}

In summary, the present work demonstrates that it is possible to prepare submicron-sized mesoporous spheres of aluminosilicates by using surfactant templating. Although the sample crystallinity is not as high as in the case of pure silica spheres prepared by a similar procedure, the high surface areas and desirable pore diameters of the aluminosilicate spheres make them good candidates for use in catalysis, sorption and related applications.

\section{References}

1. Kresge C T, Leonowicz M E, Roth W J, Varturi J C and Beck J S 1992 Nature (London) 359710

2. Yang H, Vovk G, Coombs N, Sokolov J and Ozin G A 1998 J. Mater. Chem. 8743

3. Huo Q, Feng J, Schüth F and Stucky G D 1997 Chem. Mater. 914

4. Stöber W, Fink A and Bohn E 1968 J. Colloid Interface Sci. 2662

5. Unger K K, Giesche H and Kinkel J N 1985 German Patent DE-3534, 143.2

6. Kaiser C and Unger K K 1997 German Patent DE-195 30031 A1

7. Büchel G, Unger K K, Matsumoto A and Tsutsumi K 1998 Adv. Mater. 101036

8. Qi L, Ma J, Cheng H and Zhao Z 1998 Chem. Mater. 101623

9. Grün M, Lauer L and Unger K K 1997 Adv. Mater. 9254

10. Schumacher K, Grün M and Unger K K 1999 Microporous Mesoporous Mater. 27201

11. Barrett E P, Joyner L G and Halenda P P $1951 \mathrm{~J}$. Am. Chem. Soc. 73373

12. Tanev P T and Pinnavaia T J 1996 Chem. Mater. 82068

13. Janicke M T, Landry C C, Christiansen S C, Birtalan S, Stucky G D and Chmelka B F 1999 Chem. Mater. 111342

14. Engelhardt G and Michael D 1987 High-resolution solid state NMR of silicates and zeolites (New York: John Wiley \& Sons) 